\title{
Creep Mechanisms of Calcium-Silicate-Hydrate: An Overview of Recent Advances and Challenges
}

\author{
Hailong Ye* \\ (Received April 23, 2015, Accepted September 1, 2015, Published online November 2, 2015)
}

\begin{abstract}
A critical review on existing creep theories in calcium-silicate-hydrate $(\mathrm{C}-\mathrm{S}-\mathrm{H})$ is presented with an emphasis on several fundamental questions (e.g. the roles of water, relative humidity, temperature, atomic ordering of C-S-H). A consensus on the rearrangement of nanostructures of $\mathrm{C}-\mathrm{S}-\mathrm{H}$ as a main consequence of creep, has almost been achieved. However, main disagreement still exists on two basic aspects regarding creep mechanisms: (1) at which site the creep occurs, like at interlayer, intergranular, or regions where $\mathrm{C}-\mathrm{S}-\mathrm{H}$ has a relatively higher solubility; (2) how the structural rearrangement evolutes, like in a manner of interlayer sliding, intra-transfer of water at various scales, recrystallization of gelled-like particles, or dissolutiondiffusion-reprecipitation at inter-particle boundary. The further understanding of creep behavior of $\mathrm{C}-\mathrm{S}-\mathrm{H}$ relies heavily on the appropriate characterization of its nanostructure.
\end{abstract}

Keywords: calcium-silicate-hydrate, nanostructure, creep mechanism, relative humidity, shrinkage.

\section{Introduction}

Creep is a material property commonly defined as a timedependent deformation under sustaining loads. Creep is essentially important to cementitious materials since excess deformation can negatively impact the long-term serviceability and sustainability of concrete structures (Neville 1981; Bažant 2001; Mindess et al. 2003; Singh et al. 2013; Li 2012; Ye et al. 2015). The creep behavior of cementitious materials was reported to be internally associated with the viscous nature of its main hydration product, i.e. calciumsilicate-hydrate (C-S-H), proportion of other secondary hydrated phases (e.g. portlandite), as well as externally affected by atmospheric conditions, e.g. relative humidity (RH) and temperature (Neville 1981; Bažant 2001; Powers 1968; Wittmann 2008; Alizadeh et al. 2010; Bu et al. 2015; Nguyen et al. 2013). The so-called basic creep and drying creep in cementitious materials are termed as the additional acquired deformation under constant water content (i.e. no moisture exchange with ambient and specimens, but not necessarily in saturated state) and decreasing water content (i.e. drying condition), respectively (Wittmann and Roelfstra 1980). Regardless of what type of creep, its behavior is drastically related to the interior water status in pore structure, which is further influenced by ambient RH (Ali and

Department of Civil and Environmental Engineering, The Pennsylvania State University, State College, PA 16801, USA.

*Corresponding Author; E-mail: huy131@psu.edu Copyright ( $\odot$ The Author(s) 2015. This article is published with open access at Springerlink.com
Kesler 1964; Bažant et al. 1997). For instance, cementitious material can reduce up to $80 \%$ deformation after a sever drying pre-treatment (e.g. heating to $105{ }^{\circ} \mathrm{C}$ ) (Mindess et al. 2003; Glucklich and Ishai 1962), whilst its deformation can be more than three times higher when it is exposed to a simultaneous loading and drying conditions (Mindess et al. 2003; Pickett 1942). Nevertheless, different experimental observations lead researchers to propose different creep mechanisms to explain their data. Therefore, no one creep mechanism has been universally accepted despite the extensive investigation was conducted over decades.

One of the major debates among various theories (will be elaborated in Sect. 2) lies on the role of water involving in creep, as some researchers argued that water is inessential to creep (Feldman 1972) while others believed that water is important (Powers 1968; Alizadeh et al. 2010). Additionally, for the creep mechanisms that are relevant to water, discrepancy also exists regarding the function of water at various scales in C-S-H (Powers 1968; Alizadeh et al. 2010; Glucklich and Ishai 1962; Ruetz 1968). Roughly, water in C-S-H is classified into three types: capillary water, adsorbed water and interlayer water (Powers and Brownyard 1946). However, the classification of water at various dimensions also varies slight among different nanostructures of C-S-H (Powers and Brownyard 1946; Aligizaki 2006). In addition, the role of water is reported to be different for different mechanisms, and even same type of water is reported to have different functions in different mechanisms. The first subject of this paper is to review the role of water proposed in various modern creep theories and potentially provide some insights on further research.

On the other hand, it is essentially necessary to introduce shrinkage since creep (especially drying creep) and shrinkage has some sorts of intimate relation (Wittmann 2008; 
Wittmann and Roelfstra 1980). Drying shrinkage is defined as the deformation of a specimen during drying without external loading. Both creep and shrinkage are believed to be affected by the water content in material interior, as well as external conditions. However, the mechanism between these two may not be exactly identical. It is difficult or even impossible to distinguish drying shrinkage and creep components when a material is under a circumstance of simultaneous loading and decreasing RH (i.e. drying creep) (Bažant et al. 1997). First of all, drying shrinkage (especially for irreversible component) also exhibits a time-dependent characteristic, which is intrinsically correlated to reorganization of $\mathrm{C}-\mathrm{S}-\mathrm{H}$ induced by internally drying-induced stress (e.g. capillary stress, desorption-induced solid surface tension increase, and disjoining pressure) rather than externallyapplied stress (Jennings 2000; Ye et al. 2014). All of these stresses may be considerably different in their locations and magnitudes. For instance, capillary pressure exerts stress on solid skeleton by putting adjacent particle closer, external load exerts stress on the bulk materials, while desorptioninduced stress exerts primarily on the solid surface (Kovler and Zhutovsky 2006; Beltzung and Wittmann 2005). The second part of this paper is to understand how the drying and thermal condition can potentially influence the creep performance.

Finally, this paper briefly discusses how the chemical composition, pore solution, and atomic ordering (presence of defects) of C-S-H can affect creep. In addition, the potential application of generalized creep equation on $\mathrm{C}-\mathrm{S}-\mathrm{H}$ research is also discussed.

\section{Nanostructure of Calcium Silicate Hydrate}

The nanostructure of $\mathrm{C}-\mathrm{S}-\mathrm{H}$, which is believed to be strongly related to its creep performance, is still mysterious and controversial. Therefore, this paper briefly reviews some popular models for nanostructure of $\mathrm{C}-\mathrm{S}-\mathrm{H}$ before going deep to its creep mechanism (in Sect. 3). A more comprehensive review on nanostructure of $\mathrm{C}-\mathrm{S}-\mathrm{H}$ can be found in the literature (Papatzani et al. 2015).

\subsection{Powers and Brownyard Model (First Colloidal Model) (Powers and Brownyard 1946)}

The first nanostructure model (denoted as $\mathrm{P}-\mathrm{B}$ model) that published by Powers and Brownyard, basically announces that $\mathrm{C}-\mathrm{S}-\mathrm{H}$ is a colloidal material with more or less crystalline phases. In P-B model, water is classified into three types: capillary water, physically adsorbed water (gel water) and interlayer water. As illustrated in Fig. 1a, capillary water refers to the water that is unreacted by cement hydration, primary remaining in the space between partial-/fullyhydrated particles; gel water refers to the physically adsorbed evaporable water in gel pores of $\mathrm{C}-\mathrm{S}-\mathrm{H}$; interlayer water refers to the chemically bonded non-evaporable water incorporated in the solids of $\mathrm{C}-\mathrm{S}-\mathrm{H}$ (loss of interlayer water causes dehydration of C-S-H) (Mindess et al. 2003; Powers 1958). It should be noted that the above classification is somewhat arbitrary since differentiating capillary water and gel water is not easy in realistic circumstance. As further noted by Powers, the $\mathrm{C}-\mathrm{S}-\mathrm{H}$ consists mostly of fibrous particles with straight edges, where bundles of such fibers seem to form a cross-linked network, containing some more or less amorphous interstitial material (Powers 1958).

\subsection{Feldman and Sereda Mode (Layered Structure Model) (Feldman and Sereda 1968)}

Feldman and Sereda modified the $\mathrm{P}-\mathrm{B}$ model by noticing that the $\mathrm{C}-\mathrm{S}-\mathrm{H}$ particle structurally resembles to a layered tobermorite-like crystal (denoted as F-S model) (see Fig. 1b). The significant improvement of F-S model is that it incorporates the structural function of the interlayer water in $\mathrm{C}-\mathrm{S}-\mathrm{H}$ 'particle', and emphasizes the importance of interlayer water in the mechanical and physical properties of hardened cement. As introduced later, this model argues the interlayer of $\mathrm{C}-\mathrm{S}-\mathrm{H}$ is crucial to creep of $\mathrm{C}-\mathrm{S}-\mathrm{H}$.

\subsection{Jennings and His Co-workers Model (Colloidal model) (Jennings 2000, 2008; Allen et al. 2007)}

The colloidal model (denoted as CM-I and II) proposed by Jennings and his co-workers is basically a comprehensive combination of a layer model and a colloid model (see Fig. 1c, d). The basic unit in the CM model is a grain-like particle with a thickness of few layers stacked together. These particles can cluster together to form the globules (basic building block) of about $5.6 \mathrm{~nm}$ diameter. The packing density of this globule is reported to be important to the creep of $\mathrm{C}-\mathrm{S}-\mathrm{H}$. The nano-granular nature of $\mathrm{C}-\mathrm{S}-$ $\mathrm{H}$ is experimental verified by atomic force microscopy (AFM) (Nonat 2004) and nano-identification (Vandamme and Ulm 2009; Jones and Grasley 2011), as well as theoretically proven by molecular dynamics simulation (Pellenq et al. 2008). However, different experiments or simulations give different particle sizes of $\mathrm{C}-\mathrm{S}-\mathrm{H}$ (Papatzani et al. 2015).

\section{Role of Water on Creep Mechanisms}

\subsection{The Role of Capillary Water}

The theory is in nature analogous to the concept of consolidation in soil mechanics, in which reduction in volume takes place by expulsion of water under long-term static loads. It roughly treats $\mathrm{C}-\mathrm{S}-\mathrm{H}$ as a composite filled with free liquid (i.e. not physically/chemically bonded) and solid (i.e. $\mathrm{C}-\mathrm{S}-\mathrm{H}$ solid sheets with bonded water). The external load is distributed between the bulk liquid and the solid phases, where compressed water diffuses from high to low pressure areas and, consequently, a gradual transfer of the load from the water to the solid phase takes place. Hence, the stress in the solid gradually increases causing, in turn, a gradual volumetric reduction, i.e. creep. That is, creep may be regarded as a delayed elastic deformation. Accordingly, a lower creep is to be expected in concrete with a higher modulus of elasticity and lower moisture content, which is 


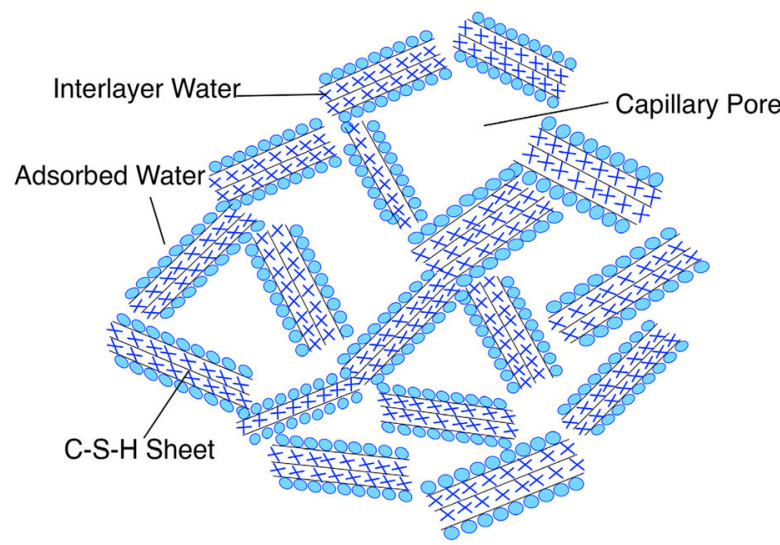

(a)

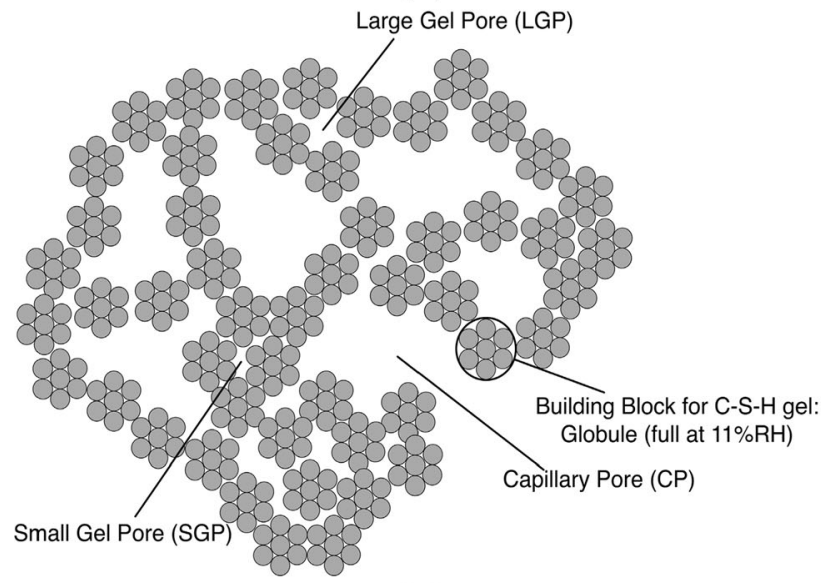

(c)

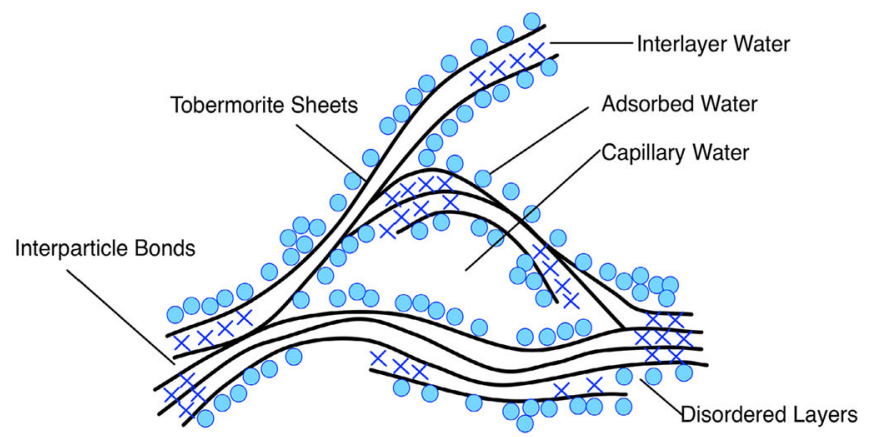

(b)

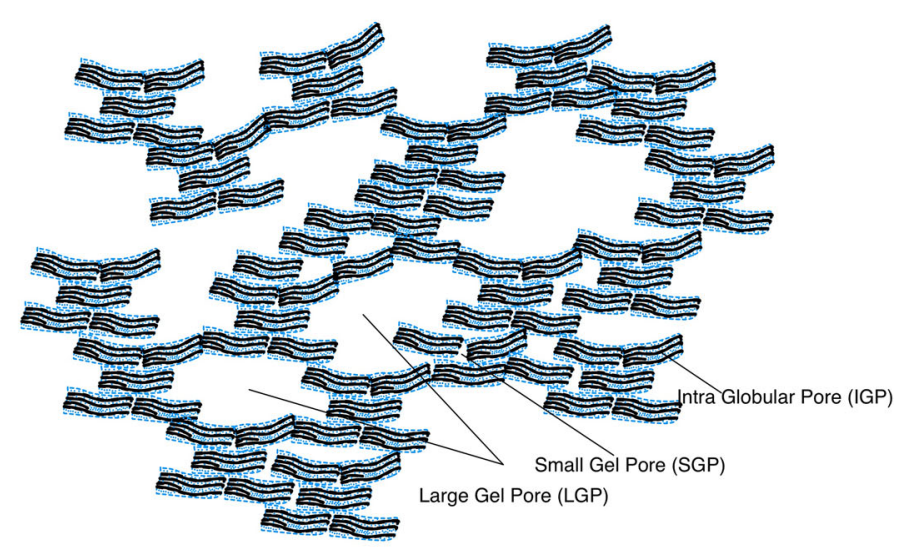

(d)

Fig. 1 Nanostructures of C-S-H (a) Powers and Brownyard model [adopted from Powers and Brownyard (1946)], b Feldman and Sereda model [adopted from Feldman and Sereda (1968)], c CM-I model [adopted from Jennings (2000)], and d CM-II model [adopted from Jennings (2008)]

however proven to be wrong by numerous experiments (Mindess et al. 2003).

The capillary water is not commonly regarded as the main status of water that contributes to creep deformation. The role of capillary water is inessential to creep mainly due to two main drawbacks: one is that it cannot account for the irreversible creep, which is believed to be in a considerable proportion of total deformation (Mindess et al. 2003). Another one is that re-immersing creeped sample into organic liquid, which can only penetrate into capillary pores but not gel and interlayer spaces, shows no volumetric change (Maekawa et al. 2003).

\subsection{The Role of Adsorbed Water (Gel Water) 3.2.1 Seepage Theory}

Based on the P-B model, Powers proposed the seepage theory, which ascribes creep due to the change in the gel water content as a manner of time-dependent seepage (Powers 1968). The process of transferring water from loadbearing areas into non-load-bearing results in the time-dependent volumetric reduction. Particularly, the external applied load violates the pre-existed balance between attractive and disjoining forces, which is gradually alleviated by the moisture diffusion among different phases. The particular type of water which is easiest to be squeezed out and responsible for main volumetric reduction is believed to be the load-bearing water or water in the hindered adsorption region. As the hindered adsorption water decrease, the preexisted disjoining pressure also decreases. It should be noted that the withdrawal of disjoining pressure is also commonly regarded as a main mechanism for drying shrinkage (Beltzung and Wittmann 2005). But different than external applied loading, the driving force for the water movement is attributed to decreasing $\mathrm{RH}$ for shrinkage. The seepage theory can account for several experimental evidence, including that oven-dried sample experiences very low creep rate (Glucklich and Ishai 1962), and drying creep is significantly higher than either dry or wet samples due to triggered water movement (Ali and Kesler 1964).

Some researchers argue that creep can occur in sealed or immersed specimens where water loss will be inhibited, and creep can even occurs for complete dried samples, both of which seems to question the seepage theory (Ali and Kesler 1964; Glucklich and Ishai 1962). It is important to note that creep occurs in sealed or immersed conditions does not necessarily mean that there is on moisture transfer and movement in material interior. It is likely the water is redistributed in various types of pores, and does not 
apparently exhibit any loss of moisture. The water in seepage theory is simply described as hindered adsorption water and commonly believed to be adsorbed water instead of capillary water.

In seepage theory, the irreversible creep is attributed to the formation of new bonds between surfaces of C-S-H when they are pressed together for the first time. Wittmann (1973) found that the creep rate only increased significantly when dried samples were re-exposed to a $\mathrm{RH}$ above approximately $45 \%$. These results cannot be accounted for by the seepage theory.

\subsubsection{Microprestress-Solidification Theory}

Extending the seepage theory, a microprestress-solidification theory was proposed by Bažant and his co-workers to predict creep using thermodynamic approach (Bažant 1972; Jirásek and Havlásek 2014). The microprestress is generated by the disjoining pressure of the hindered adsorbed water in the micropores and by very large and highly localized volume changes caused by hydration or drying. However, Bažant maintains that the same equations are valid whether the evaporable water is capillary, interlayer, or adsorbed. It is, however, necessary to define the state of the water associated with creep in order to understand and perhaps control the mechanism of creep.

\subsubsection{Viscous Shear Theory}

The viscous shear theory as proposed by Ruetz (1968) suggests that creep occurs through slip between C-S-H particles in a shear process. The sliding process takes place also in adsorbed water, in which water acts as a lubricant. Different to seepage theory, viscous shear theory considers the rearrangement of overall $\mathrm{C}-\mathrm{S}-\mathrm{H}$ particles under shear force. Although the overall tendency of $\mathrm{C}-\mathrm{S}-\mathrm{H}$ particles is to approach and contributes to volumetric reduction, the local movement of each $\mathrm{C}-\mathrm{S}-\mathrm{H}$ particle may be even more complicated rather than merely being close as disjoining pressure decreases. Since the rearrangement of $\mathrm{C}-\mathrm{S}-\mathrm{H}$ particles finally presents as a volumetric reduction, it is reasonable to assume that there should have some sorts of squeezed and redistributed water as well. The difference from seepage theory is that viscous shear theory emphasizes the role of gel water as lubricator to promote $\mathrm{C}-\mathrm{S}-\mathrm{H}$ slip rather than merely being squeezed out.

\subsubsection{Thermal Activation Energy Theory}

Wittmann (1973) proposed a thermal activation theory, which considers the absorbed water plays an indirect role on weakening interparticle bonds (Klug and Wittmann 1974). This mechanism is actually similar to viscous shear theory since weakening interaction between $\mathrm{C}-\mathrm{S}-\mathrm{H}$ particles is also the function of water lubricant. This theory also suggests that after the strength of these forces is reduced, the particles slide apart with respect to each other and creep is therefore increased. Furthermore, thermal activation theory hypothesizes that time-dependent strains are the result of thermally activated processes described as the rate-determining and structural-deforming process theory. The creep occurs towards a lower energy state when additional external energy is provided to the materials. The argument is intrinsically similar to the rearrangement and redistribution of $\mathrm{C}$ $\mathrm{S}-\mathrm{H}$ particles which evolve towards lower energy. In addition, a concept of creep centers is introduced in this theory to further distinguish the particle region with slip occurs between adjacent particles of $\mathrm{C}-\mathrm{S}-\mathrm{H}$. Klug and Wittmann (1974) concluded that individual solid particles are responsible for creep, and that the movement of single molecules of water is negligible. Admittedly, the energy-relaxed or arranged and organized structures are mostly irreversible.

\subsubsection{Rearrangement of Globules}

Based on the CM-I/II model, Jennings and his co-workers ascribe creep as a rearrangement of the globules under stress, resulting a reduction in gel porosity and enhancement of bonds which is directly correlated to the degree of silicate polymerization (Thomas and Jennings 2006). However, as noticed in CM-II model, although Jennings and his coworkers do agree that the $\mathrm{C}-\mathrm{S}-\mathrm{H}$ particle is comprised of a bunch of tobermorite-like layered sheets, how these layered sheets enter $\mathrm{C}-\mathrm{S}-\mathrm{H}$ particle rearrangement is still unknown. In other words, the structural role and physical description of adsorbed and interlayer water are not addressed in this theory. Recently, based on nano-indentation techniques, Vandamme and Ulm (2009) confirmed that creep is due to the rearrangement and tighter packing of $\mathrm{C}-\mathrm{S}-\mathrm{H}$ agglomerate around limit packing densities. As well, the structural role of water on creep is not elaborated in this argument.

\subsubsection{Dissolution-Diffusion-Reprecipitation Theory}

A recent study indicates that the nanoparticle rearrangement could be a result of dissolution-diffusion-reprecipitation process in which the grain boundary dissolves at the high stress fields and then transport and precipitate at lower stress fields (i.e. regions where solubility is lower), contributing to an overall lower energy (Pachon-Rodriguez et al. 2014). A computational model has also shown that loading can affect the dissolution-formation process of load-bearing phases at early age, which contributes to a reasonable viscous characteristic ( $\mathrm{Li}$ et al. 2015). Therefore, it would be appealing to observe the change of compositions in hydrated phases and pore solution due to loading, since other theories (e.g. denser packing of globules) do not necessarily require an evolution of phase assemblages and composition.

\subsection{The Role of Interlayer Water 3.3.1 Crystallization/Aging Theory}

Feldman and Sereda stated that adsorbed water playing a relatively minor role, whilst interlayer water in $\mathrm{C}-\mathrm{S}-\mathrm{H}$ is responsible for the major portion of creep (Feldman 1972). The interlayer theory hypothesizes that creep of cement paste is a manifestation of the gradual crystallization or aging of a poorly crystallized layered silicate material, accelerated by drying or stress. During creep, compression of $\mathrm{C}-\mathrm{S}-\mathrm{H}$ sheets causes the interactions between adjacent sheets and formation of new interlayer space. 


\subsubsection{Sliding/Translation Theory}

Based on beam-bending technique (Vichit-Vadakan and Scherer 2001), Alizadeh et al. (2010) suggested that the viscoelastic behavior of $\mathrm{C}-\mathrm{S}-\mathrm{H}$ is attributed to the sliding and translation of the $\mathrm{C}-\mathrm{S}-\mathrm{H}$ sheets under stress, which actually supports the interlayer theory proposed by Feldman and Sereda. The stress relaxation during beam-bending test is comprised of hydrodynamic relaxation (i.e. flow of liquid in the porous body) and viscous relaxation of the solid network (Vichit-Vadakan and Scherer 2001). Their study indicated that the water seepage accounts for minor proportion of total creep, but the interlayer water severs as a lubricator contributing to the layered structure sliding.

\subsection{Consensus and Discrepancy}

Although the nanostructure models of $\mathrm{C}-\mathrm{S}-\mathrm{H}$ proposed by Feldman and Sereda (layered structure) and Jennings (colloid model) are intrinsically different, the consequence of creep has almost been reached a consensus. They all attribute a featured consequence of creep as a rearrangement of nanostructures. Figure 2 illustrates the possible manners of nanostructure evolution based on different nanostructure

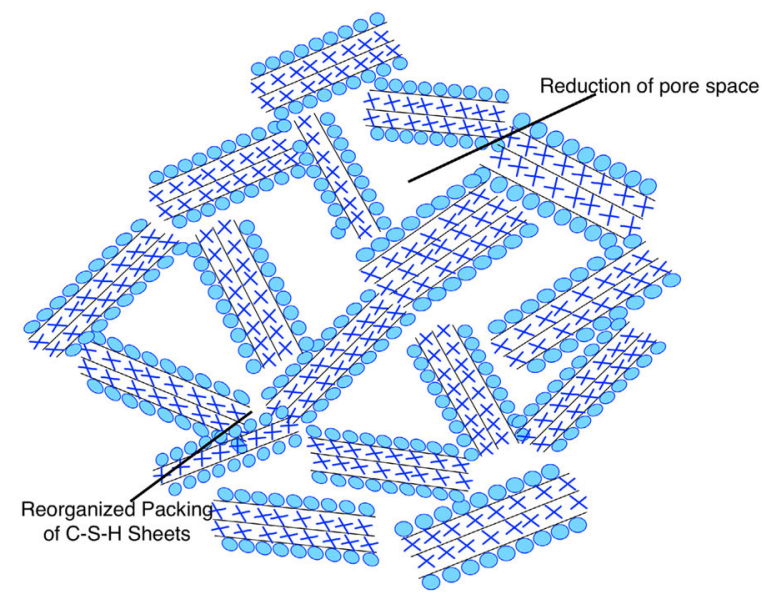

(a)

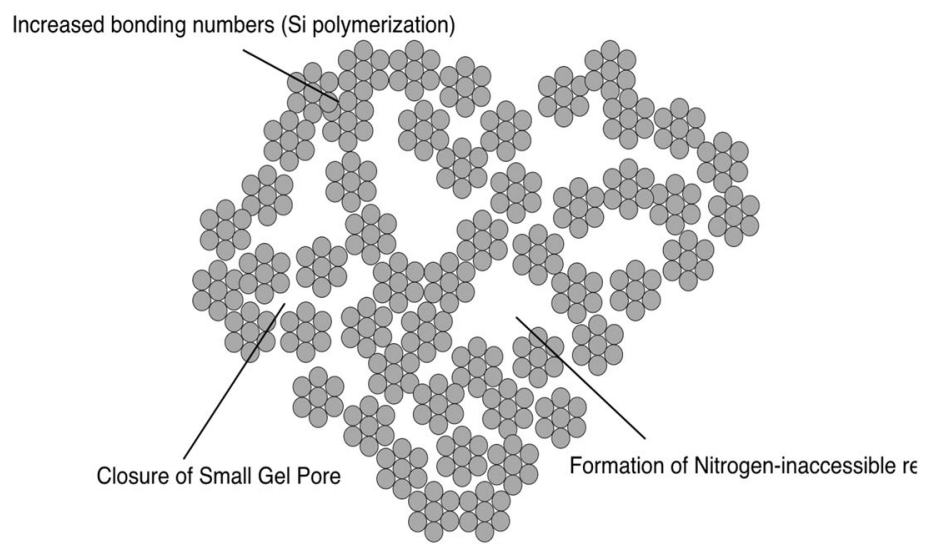

(c) models of $\mathrm{C}-\mathrm{S}-\mathrm{H}$ (see Fig. 1). Accordingly, some new features should be observed in $\mathrm{C}-\mathrm{S}-\mathrm{H}$ after structural reorganization, such as the closure of small pores, increased bonding between $\mathrm{C}-\mathrm{S}-\mathrm{H}$ chains, elongated mean chain length, formation of interlayer regions.

However, main disagreement still exists on several fundamental aspects regarding creep mechanisms:

1. At which site the creep occurs. It can be in the interlayer, intergranular (particle) or regions where the solubility of $\mathrm{C}-\mathrm{S}-\mathrm{H}$ is relatively higher (due to a locally stress concentration).

2. How the nanoscale rearrangement evolutes. In the mechanism based on Feldman and Sereda, the sliding or collapse of interlayer has been explicitly indicated, although there is no direct evidence regarding the inter-crystalline slip. However, the exact manners of how rearrangement occurs were not been extensively provided by previous researchers. It is probably be one of the interlayer sliding or dissolution-diffusion-precipitation at intergranular boundary, or intra-transfer of water, or stress and drying-induced re-crystallization of gelled-like particles.

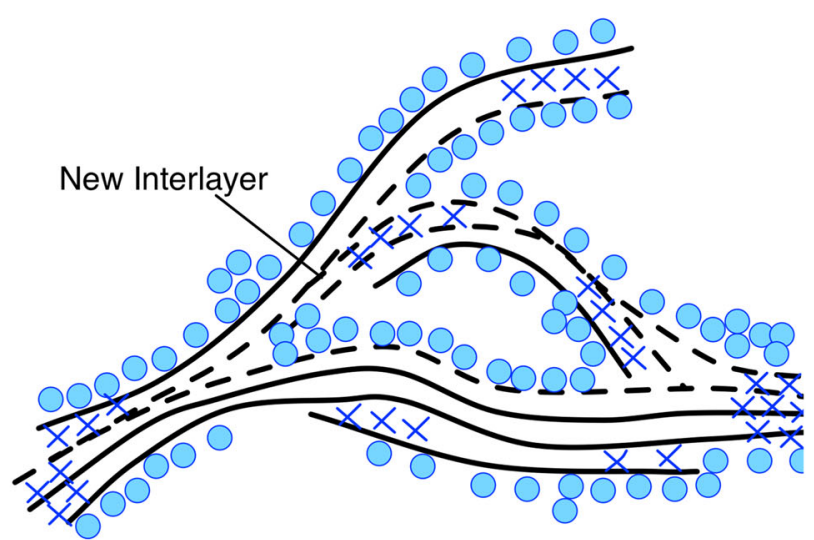

(b)

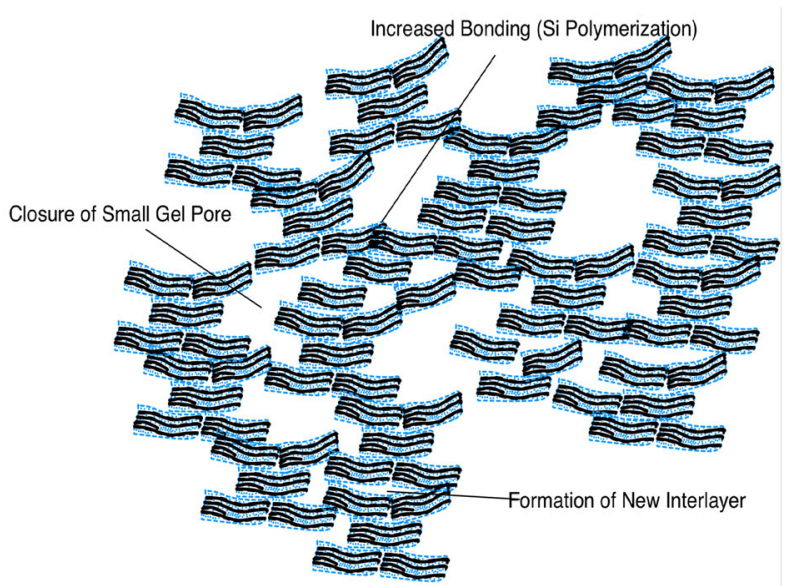

(d)

Fig. 2 Reorganized nanostructure of C-S-H (a) Powers and Brownyard model [adopted from Powers and Brownyard (1946)], b Feldman and Sereda model [adopted from Feldman and Sereda (1968)], c CM-I model [adopted from Jennings (2000)], and d CM-II model [adopted from Jennings (2008)] 
3. Regardless of at which site creep occurs, reorganization process involves some sorts of break and reform bonds, which contributes to the irreversible portion. Therefore, it is hard to differentiate the rearrangement manners by simply observing the nanostructure changes after creep using nuclear magnetic resonance spectroscopy. More attention needs to be paid on stress-induced changes of phase assemblages, chemical composition, pore solution species, and morphology of $\mathrm{C}-\mathrm{S}-\mathrm{H}$.

\section{Influence of Drying Condition}

Drying creep (also known as Pickett effect) (Wittmann and Roelfstra (1980); Pickett (1942)) is the excess of creep at drying over the sum of shrinkage and basic creep. It indicates that there is a strong correlation between creep and shrinkage, and no-linear relation between deformation and loading for drying creep. However, the exact mechanism of Pickett effect is still mysterious although several dubious hypotheses were proposed. For example, Ali and Kesler (1964) suggested drying creep is a stress-modified shrinkage, while Ruetz (1968) suggested that shearing action takes place under loading, accelerated by a concurrent moisture movement.

Thermodynamically, ambient RH plays an important role on creep by influencing several aspects: First of all, it controls the total amount of water in the $\mathrm{C}-\mathrm{S}-\mathrm{H}$ and hydrostatic capillary pressure due to drying. The capillary pressure is determined as the difference between the gas pressure above the meniscus and pressure inside the liquid (i.e. $\left.p_{c}=p_{g}-p_{l}\right)$. The well-known Kelvin-Laplace equation is commonly used to establish the mechanical and thermodynamic equilibrium between liquid and gas (Chen et al. 2013; Cohan 1938; Radlinska et al. 2008):

$$
p_{c}=-\frac{2 \gamma \cdot \cos \theta}{r_{c}}=\rho_{l} \frac{R T}{M} \ln R H
$$

where $p_{c}$ is the capillary pressure, $p_{g}$ is the gas pressure, $p_{l}$ is the liquid pressure, $\rho_{l}$ is density of liquid, $M$ is molar mass of liquid, $R$ is the universal gas constant, $T$ is temperature in Kelvin, $r_{c}$ is capillary radius at the position of meniscus, also named Kelvin radius; $\gamma$ is surface tension between pore water and vapor, $\theta$ is the contact angle denoting the hydrophilicity of pore wall. Since the liquid pressure excess significantly that of atmospheric pressure during drying (i.e. $\left.\left\|p_{l}\right\| \gg\left\|p_{g}\right\|\right)$, the gas pressure is eliminated and $p_{l} \approx p_{c}$. As a consequence of Eq. (1), at a given RH, all pores whose radii are smaller than Kelvin radius are completely filled with water, whereas larger pores have dried with layers of adsorbed water (Maekawa et al. 2003). In addition, the capillary pressure is primarily controlled by the ambient $\mathrm{RH}$, irrespective of the pore size (Radlinska et al. 2008).

Secondly, the RH controls the diffusion rate of interior moisture moving to the exposed boundary. For instance, at high $\mathrm{RH}$, the gradient of chemical potential of vapor is less and diffusion occurs slowly. Under that circumstance, the slow water movement may contribute to the long-term rearrangement of $\mathrm{C}-\mathrm{S}-\mathrm{H}$ nanoparticles or sheets. As evidenced by a recently study (Vlahinić et al. 2012), transient creep occur as the $\mathrm{RH}$ changes, mainly originating from the water movement due to the triggered chemical potential gradient. However, as mentioned before that capillary pressure decreases as RH increases, therefore there may exist a tradeoff for the influence of $\mathrm{RH}$ on the creep behaviors. In addition, $\mathrm{RH}$ affects the viscoelastic behavior of the $\mathrm{C}-\mathrm{S}-\mathrm{H}$ due to the modification of its bulk properties (Maruyama et al. 2014).

Additionally, the initial formed gel-like colloid particle in pore solution are held by a equilibrium of various forcers, like crystal-forming tendency, surface tension, solid to liquid attraction and electrical attraction and repulse. The drying of $\mathrm{C}-\mathrm{S}-\mathrm{H}$ destroys the initial quasi-balance forces in wet condition, and promotes the semi-amorphous phases to recrystallize. Admittedly, crystallization result in a volumetric reduction as the structure becomes more stable and periodic.

Another important aspect is that the stress distribution of $\mathrm{C}-\mathrm{S}-\mathrm{H}$ under simultaneous external loads and drying is extremely complicated, and has not been addressed yet. It may help to understand the creep mechanism during drying if one could unveil the constitutive relation of $\mathrm{C}-\mathrm{S}-\mathrm{H}$ in nano-scale.

\section{Effects of Temperature}

The creep performance of cementitious material is also dependent on the ambient temperature and thermal history (Bažant 1983). It was reported that short-term creep increases approximately linearly with temperature up to $80^{\circ} \mathrm{C}$, where it is about three times value at ambient temperature (Mindess et al. 2003). Regardless of the creep mechanisms involved, temperature can alter several factors those are important to creep rate. First, temperature affects the rates of dissolution, diffusion, and reaction process during any chemical action in $\mathrm{C}-\mathrm{S}-\mathrm{H}$ structural reorganization. Furthermore, temperature can slightly alter the physical properties of pore solution (e.g. viscosity) and statured vapor pressure, both of which influence the water status in concrete (Chaube et al. 1993). Another important aspect is that creep is an activation energy-associated process, which is considerably controlled by temperature as well (Green 1998). However, a pre-heating treatment can reduce the long-term creep deformation for $\mathrm{C}-\mathrm{S}-\mathrm{H}$ (Mindess et al. 2003), which may be attributed to a modification in the pore structure, (packing) density, and crystallinity of $\mathrm{C}-\mathrm{S}-\mathrm{H}$ (Thomas and Jennings 2006).

\section{Atomic Ordering of $\mathrm{C}-\mathrm{S}-\mathrm{H}$}

Considering the rearrangement of nanostructure under external or internal stress, the dislocation site (i.e. defects) in $\mathrm{C}-\mathrm{S}-\mathrm{H}$ is likely to be a major factor. Generally, a crystalline phase is more resistant to plastic deformation than its glassy state with a similar chemical composition due to the 
extensive presence of defects (Green 1998). A molecular dynamic simulation of crystalline and glassy $\mathrm{C}-\mathrm{S}-\mathrm{H}$ under shear stress indicates that glassy $\mathrm{C}-\mathrm{S}-\mathrm{H}$ has a lower shear strength and larger irreversible deformation (Manzano et al. 2013). This would be a reason why the creep of semiamorphous $\mathrm{C}-\mathrm{S}-\mathrm{H}$ prepared by synthesis is higher than that of tobermorite minerals as experimentally measured (Nguyen et al. 2014). However, it is still unknown how to accurately access the atomic ordering in $\mathrm{C}-\mathrm{S}-\mathrm{H}$ due to its small dimensions, although some advanced nanoscale characterization techniques have shed some lights on it (Nonat 2004; Lothenbach and Nonat 2015; Chae et al. 2013). In addition, the chemical composition and pore solution species are both likely to affect the structure of CS-H (Lothenbach and Nonat 2015). Therefore, it is not surprising that the $\mathrm{Ca} / \mathrm{Si}$ ratio of $\mathrm{C}-\mathrm{S}-\mathrm{H}$, additive of admixtures (e.g. slag, silica fume, colloid silica) can affect the creep performance (Alizadeh et al. 2010; Li and Yao 2001; Singh et al. 2015), probably due to a modification in the degrees of micro-defects and polymerization (Nguyen et al. 2013). On the other hands, a large incorporation of alumina and alkalis into $\mathrm{C}-\mathrm{S}-\mathrm{H}$ has shown to drastically change its structure and behaviors (Lodeiro et al. 2010). This becomes increasingly crucial to innovative alternative binders like alkali-activated slag, which has shown larger creep deformation than ordinary Portland cement (Ye et al. 2014; Häkkinen 1986).

\section{Application of the Generalized Creep Equation}

It is still unknown whether there is more than one mechanism for creep, or whether the creep mechanism varies depending on the experienced stress levels and ambient conditions (e.g. RH and temperature). Nevertheless, the primary issue regarding the creep mechanism is the criteria to differentiate various mechanisms at least qualitatively.

In the case of polycrystals (e.g. metals, minerals), the generalized creep equation has been widely implemented to differentiate the creep mechanisms, as shown below (Green 1998):

$$
\dot{\varepsilon}=\frac{A D \mu b}{k T}\left(\frac{b}{d}\right)^{m}\left(\frac{\sigma}{\mu}\right)^{n}
$$

where $\dot{\varepsilon}$ is the creep rate at secondary steady period; $A$ is a dimensionless constant; $D$ is the diffusion coefficient associated with the creep process; $\mu$ is the shear modulus; $b$ is the Burgers vector; $d$ is the grain size, $m$ is the grain size exponent and $n$ is the stress exponent. The various creep mechanisms give rise to different $m$ and $n$ values (as shown in Table 1), which can be obtained experimentally by varying the grain size of materials and applied stress.

Upon application on $\mathrm{C}-\mathrm{S}-\mathrm{H}$, the primary challenge is how to change the grain size of $\mathrm{C}-\mathrm{S}-\mathrm{H}$ nanoparticles, since varying the stress level is much easier. However, the determination of the particle size of $\mathrm{C}-\mathrm{S}-\mathrm{H}$ and how the interlayer structure incorporated into the colloid structure needs to be pre-understood. According to the CM-II model, the interlayer is perfectly incorporated and stacked together to form a grain called globules, while in Feldman and Sereda model, the separation between particle boundary and interlayer is not clear. By admitting the CM-II model, another important aspect before applying the generalized creep equation is how to vary the particle size experimentally. Physically, the application of stress and high temperature evaluation could possibly reduce the grain size for some

Table 1 Creep equation exponents and diffusion paths for various creep mechanisms [adopted from Green (1998)]

\begin{tabular}{|c|c|c|c|}
\hline Creep mechanism & $m$ & $n$ & Diffusion path \\
\hline \multicolumn{4}{|c|}{ Dislocation creep mechanisms } \\
\hline $\begin{array}{l}\text { Dislocation glide climb (climb } \\
\text { controlled) }\end{array}$ & 0 & $4-5$ & Lattice \\
\hline $\begin{array}{l}\text { Dislocation glide climb, glide } \\
\text { controlled }\end{array}$ & 0 & 3 & Lattice \\
\hline Dissolution of dislocation loops & 0 & 4 & Lattice \\
\hline Dislocation climb without glide & 0 & 3 & Lattice \\
\hline Dislocation climb by pipe diffusion & 0 & 5 & Dislocation core \\
\hline \multicolumn{4}{|c|}{ Diffusional creep mechanisms } \\
\hline Vacancy flow through grains & 2 & 1 & Lattice \\
\hline Vacancy flow along boundaries & 3 & 1 & Grain boundary \\
\hline Interface reaction control & 1 & 2 & Lattice/grain boundary \\
\hline \multicolumn{4}{|c|}{ Grain boundary sliding mechanisms } \\
\hline Sliding with liquid & 3 & 1 & Liquid \\
\hline $\begin{array}{l}\text { Sliding without liquid (diffusion } \\
\text { control) }\end{array}$ & $2-3$ & 1 & Lattice/grain boundary \\
\hline
\end{tabular}


materials, like metals (Green 1998). However, CM-II model emphasizes that both of them basically increase the packing density of grains rather than reduce the size. Nevertheless, it is still mysterious whether the grain boundary involved in creep behavior is identical to that described by CM-II.

\section{Summaries}

Creep of cementitious materials is a complicated phenomenon, which is influenced by the loading magnitude/ history, temperature, relative humidity, thermal and drying histories, as well as chemical composition and structure of $\mathrm{C}-\mathrm{S}-\mathrm{H}$ itself. These mechanical- thermal- physical- chemical interactions are simultaneously presented and non-linearly coupled. Understanding the creep mechanism requires a proper pre-examination of the nanostructure of $\mathrm{C}-\mathrm{S}-\mathrm{H}$. The exact creep mechanism should be reflected by a concurrent evolution of nanostructure, chemical composition of hydrated phases, and pore solution composition during creep. Although a combination of various advanced technique for nanostructure characterization may shed some lights on the creep mechanism, there still exist several disagreements among the results obtained by different techniques. As elaborated in the text, two fundamental questions regarding creep are still unclarified yet. One is 'where does the creep take place', and another is 'how does creep occur'. Answering these questions will provide the theoretical backgrounds on how to mitigate creep, quantitatively predict creep deformation, and enhance the volumetric stability of cementitious materials.

\section{Acknowledgments}

The author would like to thank the anonymous referees for improving the quality of this manuscript.

\section{Open Access}

This article is distributed under the terms of the Creative Commons Attribution 4.0 International License (http://creativecommons.org/licenses/by/4.0/), which permits unrestricted use, distribution, and reproduction in any medium, provided you give appropriate credit to the original author(s) and the source, provide a link to the Creative Commons license, and indicate if changes were made.

\section{References}

Ali, I., \& Kesler, C. E. (1964). Mechanisms of creep in concrete. Champaign, IL: University of Illinois.

Aligizaki, K. K. (2006). Pore structure of cement-based materials: Testing, interpretation and requirements. Boca Raton, FL: CRC Press.
Alizadeh, R., Beaudoin, J. J., \& Raki, L. (2010). Viscoelastic nature of calcium silicate hydrate. Cement \& Concrete Composites, 32(5), 369-376.

Allen, A. J., Thomas, J. J., \& Jennings, H. M. (2007). Composition and density of nanoscale calcium-silicate-hydrate in cement. Nature Materials, 6(4), 311-316.

Bažant, Z. (1972). Thermodynamics of interacting continua with surfaces and creep analysis of concrete structures. Nuclear Engineering and Design, 20(2), 477-505.

Bažant, Z. P. (1983). Mathematical model for creep and thermal shrinkage of concrete at high temperature. Nuclear Engineering and Design, 76(2), 183-191.

Bažant, Z. P. (2001). Prediction of concrete creep and shrinkage: Past, present and future. Nuclear Engineering and Design, 203(1), 27-38.

Bažant, Z. P., Hauggaard, A. B., Baweja, S., \& Ulm, F.-J. (1997). Microprestress-solidification theory for concrete creep. I: Aging and drying effects. Journal of Engineering Mechanics, 123(11), 1188-1194.

Beltzung, F., \& Wittmann, F. H. (2005). Role of disjoining pressure in cement based materials. Cement and Concrete Research, 35(12), 2364-2370.

$\mathrm{Bu}$, Y., Saldana, C., Handwerker, C., \& Weiss, J. (2015). The role of calcium hydroxide in the elastic and viscoelastic response of cementitious materials: A Nanoindentation and SEM-EDS Study (pp. 25-34). Nanotechnology in Construction: Springer.

Chae, S. R., Moon, J., Yoon, S., Bae, S., Levitz, P., Winarski, R., et al. (2013). Advanced nanoscale characterization of cement based materials using X-ray synchrotron radiation: A review. International Journal of Concrete Structures and Materials, 7(2), 95-110.

Chaube, R., Shimomura, T., \& Maekawa, K. (1993). Multiphase water movement in concrete as a multi-component system. In RILEM proceedings (p. 139). Chapman \& Hall.

Chen, H., Wyrzykowski, M., Scrivener, K., \& Lura, P. (2013). Prediction of self-desiccation in low water-to-cement ratio pastes based on pore structure evolution. Cement and Concrete Research, 49, 38-47.

Cohan, L. H. (1938). Sorption hysteresis and the vapor pressure of concave surfaces. Journal of the American Chemical Society, 60(2), 433-435.

Feldman, R. F. (1972). Mechanism of creep of hydrated Portland cement paste. Cement and Concrete Research, 2(5), 521-540.

Feldman, R. F., \& Sereda, P. J. (1968). A model for hydrated Portland cement paste as deduced from sorption-length change and mechanical properties. Matériaux et Construction, 1(6), 509-520.

Glucklich, J., \& Ishai, O. (1962). Creep mechanism in cement mortar. ACI Journal Proceedings, 59(7), 923-948.

Green, D. J. (1998). An introduction to the mechanical properties of ceramics. Cambridge, UK: Cambridge University Press.

Häkkinen, T. (1986). Properties of alkali-activated slag concrete. Valtion teknillinen tutkimuskeskus, Betoni-ja silikaattitekniikan laboratorio. 
Jennings, H. M. (2000). A model for the microstructure of calcium silicate hydrate in cement paste. Cement and Concrete Research, 30(1), 101-116.

Jennings, H. M. (2008). Refinements to colloid model of CSH in cement: CM-II. Cement and Concrete Research, 38(3), 275-289.

Jirásek, M., \& Havlásek, P. (2014). Microprestress-solidification theory of concrete creep: Reformulation and improvement. Cement and Concrete Research, 60, 51-62.

Jones, C. A., \& Grasley, Z. C. (2011). Short-term creep of cement paste during nanoindentation. Cement \& Concrete Composites, 33(1), 12-18.

Klug, P., \& Wittmann, F. (1974). Activation energy and activation volume of creep of hardened cement paste. Materials Science and Engineering, 15(1), 63-66.

Kovler, K., \& Zhutovsky, S. (2006). Overview and future trends of shrinkage research. Materials and Structures, 39(9), $827-847$.

Li, V. C. (2012). Tailoring ECC for special attributes: A review. International Journal of Concrete Structures and Materials, 6(3), 135-144.

Li, X., Grasley, Z., Garboczi, E., \& Bullard, J. (2015). Modeling the apparent and intrinsic viscoelastic relaxation of hydrating cement paste. Cement \& Concrete Composites, $55,322-330$.

Li, J., \& Yao, Y. (2001). A study on creep and drying shrinkage of high performance concrete. Cement and Concrete Research, 31(8), 1203-1206.

Lodeiro, I. G., Fernández-Jimenez, A., Palomo, A., \& Macphee, D. (2010). Effect on fresh CSH gels of the simultaneous addition of alkali and aluminium. Cement and Concrete Research, 40(1), 27-32.

Lothenbach, B., \& Nonat, A. (2015). Calcium silicate hydrates: Solid and liquid phase composition. Cement and Concrete Research, 78, 57-70.

Maekawa, K., Ishida, T., \& Kishi, T. (2003). Multi-scale modeling of concrete performance. Journal of Advanced Concrete Technology, 1(2), 91-126.

Manzano, H., Masoero, E., Lopez-Arbeloa, I., \& Jennings, H. M. (2013). Shear deformations in calcium silicate hydrates. Soft Matter, 9(30), 7333-7341.

Maruyama, I., Nishioka, Y., Igarashi, G., \& Matsui, K. (2014). Microstructural and bulk property changes in hardened cement paste during the first drying process. Cement and Concrete Research, 58, 20-34.

Mindess, S., Young, J. F., \& Darwin, D. (2003). Concrete (2nd ed.). Upper Saddle River: Pearson Education, Inc.

Neville, A. (1981). Properties of concrete (3rd ed.). London: Pitman Publishing Ltd.

Nguyen, D.-T., Alizadeh, R., Beaudoin, J. J., Pourbeik, P., \& Raki, L. (2014). Microindentation creep of monophasic calcium-silicate-hydrates. Cement \& Concrete Composites, 48, 118-126.

Nguyen, D.-T., Alizadeh, R., Beaudoin, J., \& Raki, L. (2013). Microindentation creep of secondary hydrated cement phases and C-S-H. Materials and Structures, 46(9), $1519-1525$.
Nonat, A. (2004). The structure and stoichiometry of CSH. Cement and Concrete Research, 34(9), 1521-1528.

Pachon-Rodriguez, E. A., Guillon, E., Houvenaghel, G., \& Colombani, J. (2014). Wet creep of hardened hydraulic cements - Example of gypsum plaster and implication for hydrated Portland cement. Cement and Concrete Research, 63, 67-74.

Papatzani, S., Paine, K., \& Calabria-Holley, J. (2015). A comprehensive review of the models on the nanostructure of calcium silicate hydrates. Construction and Building Materials, 74, 219-234.

Pellenq, R.-M., Lequeux, N., \& Van Damme, H. (2008). Engineering the bonding scheme in $\mathrm{C}-\mathrm{S}-\mathrm{H}$ : The iono-covalent framework. Cement and Concrete Research, 38(2), 159-174.

Pickett, G. (1942). The effect of Chang in moisturecontent on the crepe of concrete under a sustained load. ACI Journal Proceedings, 38, 333-356.

Powers, T. C. (1958). Structure and physical properties of hardened Portland cement paste. Journal of the American Ceramic Society, 41(1), 1-6.

Powers, T. (1968). The thermodynamics of volume change and creep. Matériaux et Construction, 1(6), 487-507.

Powers, T. C., \& Brownyard, T. L. (1946). Studies of the physical properties of hardened Portland cement paste. ACI Journal Proceedings, 43(9), 249-336.

Radlinska, A., Rajabipour, F., Bucher, B., Henkensiefken, R., Sant, G., \& Weiss, J. (2008). Shrinkage mitigation strategies in cementitious systems: A closer look at differences in sealed and unsealed behavior. Transportation Research Record: Journal of the Transportation Research Board., 2070(1), 59-67.

Ruetz, W. (1968). A hypothesis for the creep of hardened cement paste and the influence of simultaneous shrinkage. In Proceedings of the structure of concrete and its behavior under load (pp. 365-387).

Singh, L. P., Goel, A., Bhattachharyya, S. K., Ahalawat, S., Sharma, U., \& Mishra, G. (2015). Effect of morphology and dispersibility of silica nanoparticles on the mechanical behaviour of cement mortar. International Journal of Concrete Structures and Materials, 9(2), 1-11.

Singh, B. P., Yazdani, N., \& Ramirez, G. (2013). Effect of a time dependent concrete modulus of elasticity on prestress losses in bridge girders. International Journal of Concrete Structures and Materials, 7(3), 183-191.

Thomas, J. J., \& Jennings, H. M. (2006). A colloidal interpretation of chemical aging of the CSH gel and its effects on the properties of cement paste. Cement and Concrete Research, 36(1), 30-38.

Vandamme, M., \& Ulm, F.-J. (2009). Nanogranular origin of concrete creep. Proceedings of the National Academy of Sciences, 106(26), 10552-10557.

Vichit-Vadakan, W., \& Scherer, G. (2001). Beam-bending method for permeability and creep characterization of cement paste and mortar. In Proceedings of the 6th international conference on creep, shrinkage and durability mechanics of concrete and other quasi-brittle materials (pp. 27-32). Cambridge, MA: Elsevier. 
Vlahinić, I., Thomas, J. J., Jennings, H. M., \& Andrade, J. E. (2012). Transient creep effects and the lubricating power of water in materials ranging from paper to concrete and Kevlar. Journal of the Mechanics and Physics of Solids, 60(7), 1350-1362.

Wittmann, F. (1973). Interaction of hardened cement paste and water. Journal of the American Ceramic Society, 56(8), 409-415.

Wittmann, F. (2008). Heresies on shrinkage and creep mechanisms. In Proceedings of the 8th international conference on creep, shrinkage and durability mechanics of concrete and concrete structures (CONCREEP 8) (pp. 3-9).
Wittmann, F., \& Roelfstra, P. (1980). Total deformation of loaded drying concrete. Cement and Concrete Research, 10(5), 601-610.

Ye, H., Cartwright, C., Rajabipour, F., \& Radlińska, A. (2014). Effect of drying rate on shrinkage of alkali-activated slag cements. In 4th international conference on the durability of concrete structure (ICDCS 2014) (pp. 254-261). Purdue University.

Ye, H., Fu, C., Jin, N., \& Jin, X. (2015). Influence of flexural loading on chloride ingress in concrete subjected to cyclic drying-wetting condition. Computers and Concrete, 15(2), 183-198. 